\title{
The influence of insulin antibody levels on the plasma profiles and action of subcutaneously injected human and bovine short acting insulins
}

\author{
A.J. Francis, I. Hanning and K. G. M. M. Alberti \\ Department of Medicine, The Medical School, Newcastle upon Tyne, UK
}

Summary. The influence of moderate and low insulin antibody levels on insulin absorption and plasma free insulin profiles is uncertain. Two groups of six C-peptide negative diabetic patients, one with low $(3.8 \pm 0.8 \mu / 1)$ and one with moderate $(16.4 \pm 2.0 \mu \mathrm{g} / \mathrm{l})$ serum insulin antibody levels, were studied. Subjects were given $0.3 \mathrm{U} / \mathrm{kg}$ neutral human or acid bovine soluble insulin subcutaneously in random order before breakfast on separate days. Moderate antibody levels significantly blunted the rise in plasma free insulin that followed injection of the human and bovine insulins $(p<0.05)$. The rise in blood glucose after breakfast was significantly greater in patients with moderate antibody levels $(p<0.05)$ and more marked following the bovine than the human insulin $(p<0.05)$. Plasma free insulin, blood glucose and 3-hydroxybutyrate profiles suggest that acid bovine soluble insulin has a significantly more protracted action than neutral human insulin.

Key words: Type 1 (insulin-dependent) diabetes mellitus, insulin antibodies, insulin absorption.
Insulin binding antibodies at high titre may cause insulin resistance [1, 2]. They may also prolong the action of injected insulin but such an effect has only been convincingly demonstrated during artificially induced severe insulin deficiency [3-5]. It is not known whether the more moderate levels of insulin antibodies found in the majority of insulin treated diabetic patients significantly affect the pharmacokinetics of insulin therapy. This could be of particular importance when attempting to mimic meal-time insulin secretory patterns. We have therefore examined the effect of moderate levels of insulin antibodies on the absorption and action of human and bovine soluble insulins.

\section{Subjects and methods}

\section{Subjects}

Two groups of six Type 1 (insulin-dependent) diabetic patients were studied: one group had serum insulin binding capacity for porcine and bovine insulins below $10 \mu / 1$, whilst the second group had binding above $10 \mu / 1$ (Table 1). The groups were matched for age, duration of diabetes, insulin dose and body mass index $\left(\mathrm{kg} / \mathrm{m}^{2}\right)$.

Informed consent was given by patients and the study was approved by the Newcastle upon Tyne Health Authority Ethical Committee.

\section{Protocol}

To deplete residual subcutaneous insulin depots, patients were treated with short acting insulin alone for $24 \mathrm{~h}$ before the study, the last dose being given at 22.00 hours. At 08.00 hours on the day of study, patients were given either $0.3 \mathrm{U} / \mathrm{kg}$ highly purified human neutral soluble insulin (Human Actrapid, Novo Industri, Bagsvaerd, Denmark) or bovine acid soluble (Wellcome Medical Division, Crewe, UK) in random order. The study was repeated with the other insulin preparation approximately 1 week later.

All injections were given into the anterior abdominal wall $10 \mathrm{~cm}$ lateral to the umbilicus using a $12.7 \mathrm{~mm}$ needle inserted vertically to the hilt by one physician. Patients ate their normal breakfast and lunch at 08.15 and 12.00 hours respectively (Table 1 ), and remained at rest in a chair throughout the study with the injection site covered by their normal indoor clothing. Before the study a polyethylene cannula was inserted into a forearm vein and its patency maintained by flushing with physiological saline. Two baseline blood samples were drawn, and blood taken every $15 \mathrm{~min}$ for $2 \mathrm{~h}$, and every $30 \mathrm{~min}$ until $8 \mathrm{~h}$. Blood for estimation of glucose, lactate, pyruvate, glycerol, alanine and 3-hydroxybutyrate was deproteinised immediately in perchloric acid $(0.5 \mathrm{~mol} / \mathrm{l})$ and assayed by fluorimetric techniques [6]. Plasma for measurement of free insulin was separated by centrifugation for $2 \mathrm{~min}$ and antibodies precipitated immediately with potyethylene glycol [7]. Extracts were stored at $-20^{\circ} \mathrm{C}$ and measured by radioimmunoassay [8]. Human insulin was used as standard, and cross reactivity with bovine insulin was $100 \%$. A serum sample was drawn on the first day of study for measurement of insulin binding capactiy by an immunochemical method [9], using human, porcine and bovine insulin as ligands. 
Table 1. Clinical characteristics of patients studied

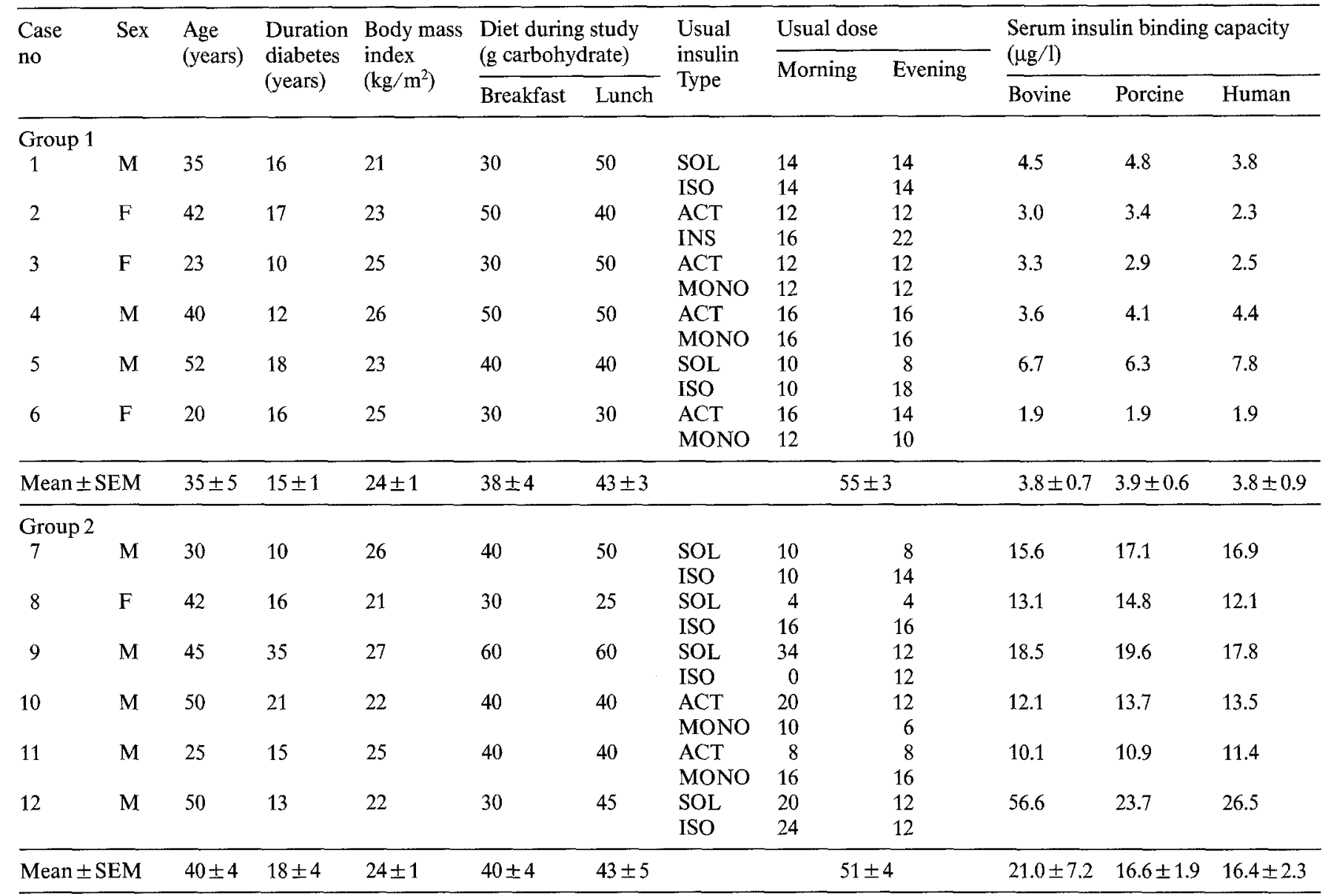

All patients had undetectable serum C-peptide levels $(<0.02 \mathrm{nmol} / 1) 90 \mathrm{~min}$ following breakfast and normal plasma creatinine concentrations. $\mathrm{SOL}=$ Bovine acid soluble insulin purified by recrystallization only; ISO = bovine isophane insulin; ACT = porcine neutral soluble insulin, highly purified; $\mathrm{MONO}=$ porcine lente insulin, highly purified

\section{Statistical analysis}

Results are expressed as mean \pm SEM. The areas under the free insulin and metabolic curves were calculated trapezoidally. Analysis was by Students paired or unpaired t-test or by Spearman's rank correlation unless otherwise stated. To avoid errors due to comparison of repeated measures over time, statistical tests were performed on areas under the free insulin or metabolite curves. Where a significant difference was found differences at individual time points have also been shown in the figures. A computerised curve fitting program was used to describe the mean plasma free insulin profiles. A satisfactory fit was obtained using one rising and one falling exponential, with a lag phase before insulin was detectable [10].

\section{Results}

\section{Insulin antibody concentrations}

Serum insulin binding capacities for each patient are shown in Table 1. Binding capacities were almost identical for each of the three insulin species tested except in patient 12 who had the highest binding capacity and whose serum showed greater affinity for bovine than porcine or human insulins.

\section{Effect of insulin antibody concentration}

Moderate levels of insulin antibodies blunted the rise in plasma free insulin levels following subcutaneous injection of both neutral human and acid bovine insulins (Fig. 1). The areas under the plasma free insulin curves were significantly greater $(p<0.05)$ in patients with low antibodies for the first and second hours after human insulin and the first hour after bovine insulin. There was a significant negative correlation between the insulin antibody level of each patient and the area under the plasma free insulin curve in the first hour after injection $\left(r=-0.63\right.$. Spearman's $\left.r_{s}=-0.58, p<0.05\right)$ (Fig. 2). As intermediate-acting insulin had been withheld the previous evening patients were insulin deficient and blood glucose levels were high at the beginning of the study $(12.1 \pm 1.3 \mathrm{mmol} / \mathrm{l}$ moderate antibody group, $18.7 \pm 1.4$ low antibody group). However, the rise in blood glucose after breakfast was greater in the group with moderate antibody levels than in the group with low antibody levels (Fig.3), the incremental area under the blood glucose curve being significantly greater $(p<0.05)$ in the first hour after injection of bovine insulin. 

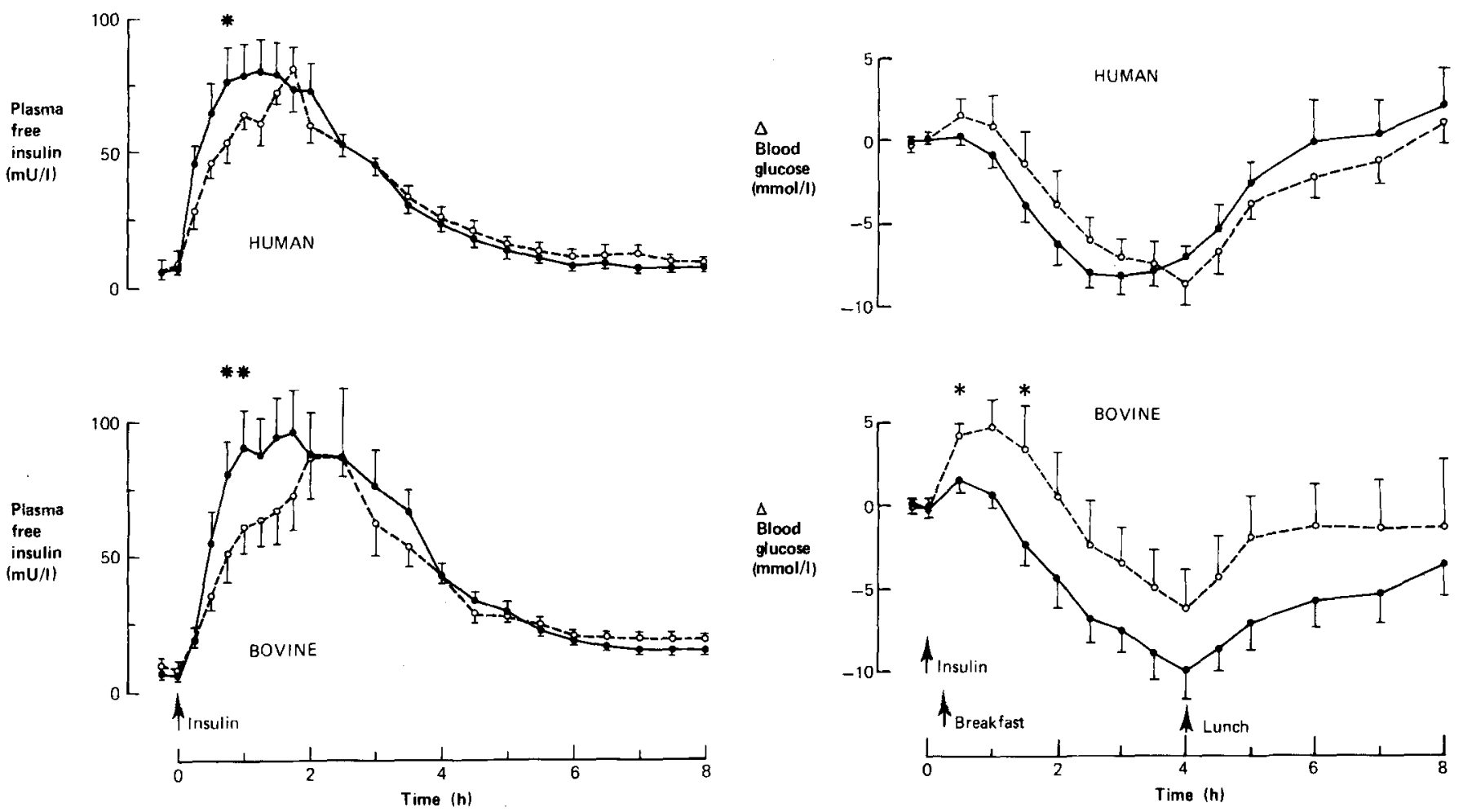

Fig.1. Plasma free insulin profiles after subcutaneous injection of $0.3 \mathrm{U} / \mathrm{kg}$ soluble insulin in C-peptide deficient patients with low $(<$ $10 \mu \mathrm{g} / \mathrm{l})(-2)$ and moderate $(\mathrm{O} \ldots \mathrm{O})$ insulin antibody levels. Results for human and bovine insulins are shown in the upper and lower panels respectively

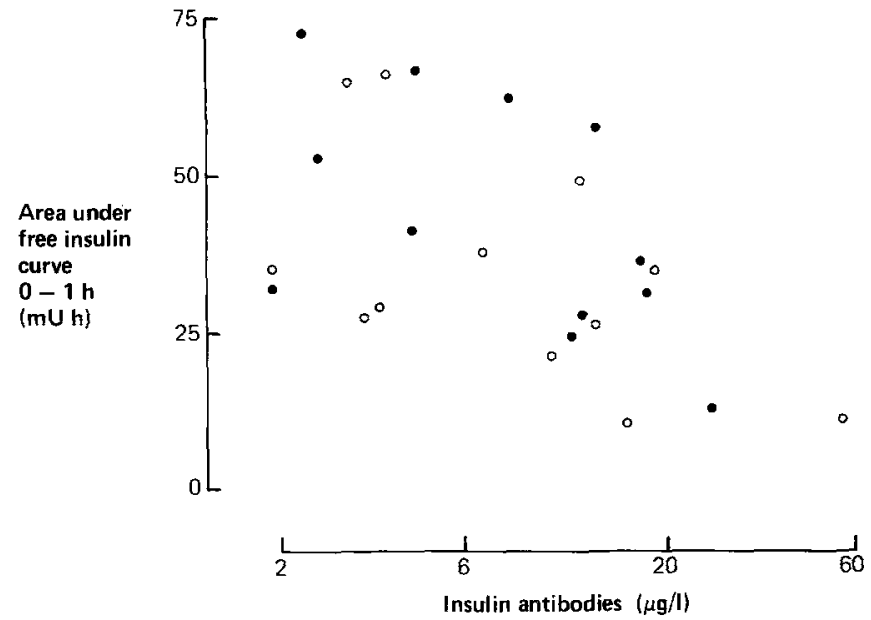

Fig. 2. Relationship between insulin binding capacity and calculated area under free insulin curve in the first hour after injection. Results for human (O) and bovine $(O)$ insulin are shown separately $\left(r=-0.63, \mathrm{r}_{\mathrm{s}}(\right.$ Spearman $\left.)=-0.58, p<0.05\right)$

Free insulin profiles were similar in the low and moderate antibody groups from $2 \mathrm{~h}$ after injection until the end of the study (Fig.1). However the computer calculated absorption rate suggest a slightly longer half life in patients with moderate antibody levels (87 versus $75 \mathrm{~min}$ ). The rise in blood glucose concentration following lunch was similar in the groups with low and moderate antibodies during treatment with either insulin

Fig.3. Blood glucose profiles after subcutaneous injection of $0.3 \mathrm{U} /$ $\mathrm{kg}$ soluble insulin in patients with low $(<10 \mu \mathrm{g} / \mathrm{l})(-)$ and moderate $(0 \ldots-0)$ insulin antibody levels

(Fig.3), as was the rate of rise in 3-hydroxybutyrate which occurred toward the end of the study as free insulin levels declined (Fig.4),

\section{Effect of insulin species and preparation}

The rise in plasma free insulin concentration from baseline was more rapid with neutral human than with acid bovine insulin but this was not statistically significant. However the rise in blood glucose in response to breakfast was significantly less following the human insulin than the bovine insulin $(p<0.05$ in the first hour after injection).

Plasma free insulin levels were sustained at higher levels following injection of acid bovine insulin than neutral human insulin. The area under the plasma free insulin curve was significantly greater $4-8 \mathrm{~h}$ after injection of the bovine insulin than after the human insulin $(p<0.01)$. The calculated absorption rate, once steady state had been established, corresponded to a half life of $62 \mathrm{~min}$ for human and $92 \mathrm{~min}$ for bovine insulin. Blood glucose levels correspondingly rose less after lunch with the bovine than with the human insulin $(p<0.05)$. Blood 3-hydroxybutyrate levels remained significantly lower between 5 and $8 \mathrm{~h}$ after acid bovine insulin injection than after neutral human insulin $(p<$ 0.05 ). There was no significant difference in blood lactate, pyruvate, glycerol or alanine profiles. 

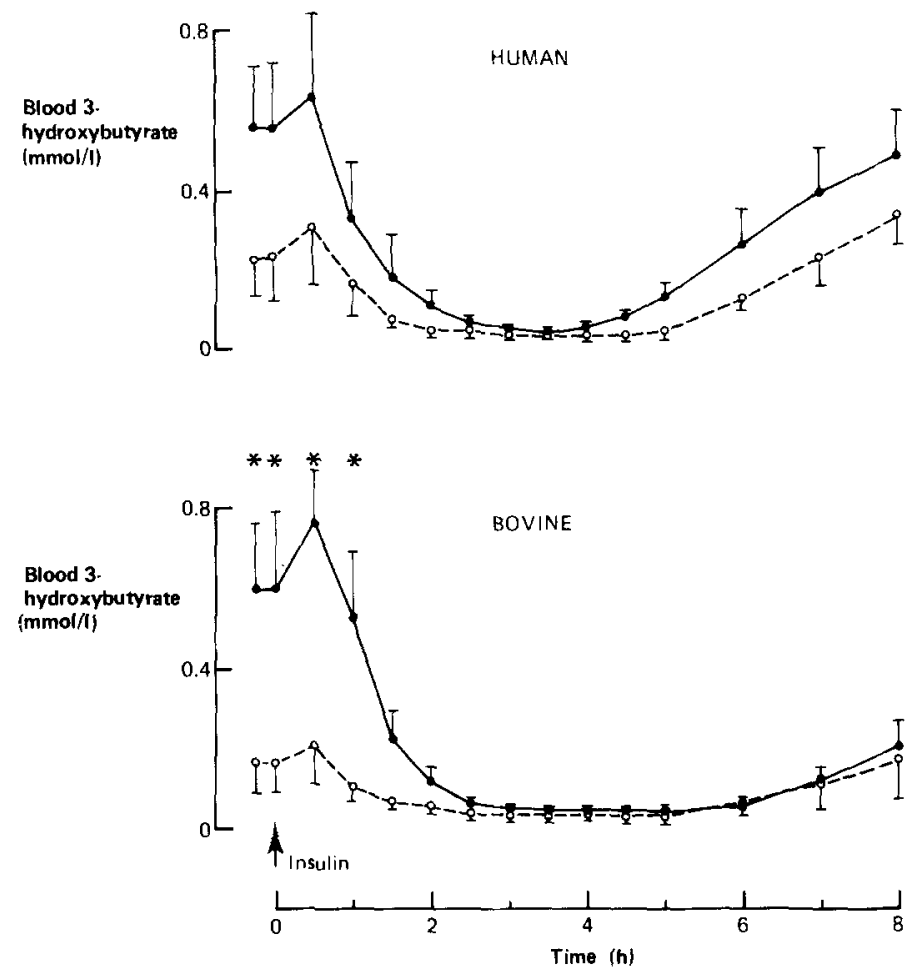

Fig.4. 3-hydroxybutyrate profiles after subcutaneous injection of $0.3 \mathrm{U} / \mathrm{Kg}$ soluble insulin in patients with low $(<10 \mu \mathrm{g} / \mathrm{l})(-\infty)$ and moderate $\left(\mathrm{O}_{-}-\mathrm{O}\right)$ insulin antibody levels

\section{Discussion}

The results suggest that moderate levels of circulating insulin binding antibodies are associated with a delay in the rise of plasma insulin concentrations and the onset of action of both neutral human and acid bovine insulins (Figs. 1-3). From this study it is not possible to determine whether this is due to delay in the onset of absorption from the subcutaneous tissue or to the binding of insulin by antibodies after absorption into the circulation. However assuming that extracellular fluid comprises $20 \%$ of body weight, and that $\lg G$ concentration in the extravascular component is about $60 \%$ of that in serum, one may calculate that in our patients with moderate antibody levels the total antibody pool could, under maximal conditions, bind 3-8 units of insulin and thus could exert considerable influence on the dynamics of insulin action.

In order to mimic the normal meal-time insulin secretory pattern, the pre-prandial insulin injection should have a rapid onset of action, and insulin activity should return to base line in the post-absorptive state. In this study we found that differences in blood glucose following breakfast persisted well beyond the observed difference in free insulin levels. This suggests that the timing of the onset of insulin action to meals is of critical importance. In this respect the choice of injection site is important as absorption from the abdominal wall, the site chosen for this study, is more rapid than from the arm or leg $[11,12]$. In addition administration of insulin thirty minutes before breakfast may significantly reduce the post-prandial peak in blood glucose [13]. By adjusting the time of the pre-prandial insulin injection it may be possible to minimise the small difference in the onset of action we have found between the human and bovine insulin preparations. It is unlikely, however, to compensate for the more prolonged blunting of absorption seen in our patients with moderate antibody levels, as peak plasma free insulin levels were not achieved until $2 \mathrm{~h}$ after injection (Fig. 1 ).

Several studies [3-5] have suggested that insulin antibodies may prolong insulin action, with speculation that they may act as a buffer gradually releasing 'free' insulin to the circulation. We did not find that moderate levels of antibodies, when compared with low levels, significantly prolonged the action of human or bovine insulin over the eight hours of study. This discrepancy is most likely explained by the differing conditions of study. Whilst we examined the absorption of subcutaneously injected soluble insulin, the earlier studies [3-5] examined the role of antibodies during acute insulin deprivation induced by cessation of intravenous insulin infusion. If antibodies do play a useful role in maintaining background insulin levels this may be of greatest importance in the latter part of the night when free insulin levels are in decline with consequent deterioration in metabolic control [14]. In our study, when no intermediate acting insulin had been given the previous day, this effect was evident. The group of patients with moderate antibody levels had significantly lower fasting levels of 3-hydroxybutyrate (Fig. 4) and blood glucose (12.1 \pm 1.3 versus $18.7 \pm 1.4 \mathrm{mmol} / 1, p<0.05$ ). This finding should however be interpreted with caution. The study was designed to assess the effect of antibodies on the meal-time action of short-acting insulin and it would be inappropriate to extrapolate these findings to overnight control with longer acting insulin preparations. In addition more patients ( 4 of 6 ) in the moderate antibody group had received acid bovine insulin the evening before study, and we have shown that the bovine soluble insulin had a more protracted action irrespective of antibody levels.

Moderate levels of insulin binding antibodies thus markedly blunt the onset of action of short acting insulins. We did not find that insulin antibodies significantly extended the action of subcutaneous injected short acting insulin but as the study was not designed to assess total duration of action such an effect may have been missed.

Acknowledgements. We are grateful to Novo Laboratories Ltd and the British Diabetic Association for financial support. The kind help of the staff of Ward 2, Newcastle General Hospital is gratefully acknowledged. 


\section{References}

1. Anderson OO, Egeberg $J(1977)$ The clinical significance of insulin antibodies. Acta Paed Scand 270: 63-68

2. Reeves WG, Allen BR, Tattersall RB (1980) Insulin-induced lipoatrophy: evidence for an immune pathogenesis. Br Med $\mathrm{J} 280$ : $1500-1503$

3. Madsbad S, Alberti KGMM, Binder C, Burrin JM, Faber OK, Krakup T, Regeur L (1979) Role of residual insulin secretion in protecting against ketoacidosis in insulin - dependent diabetics. Br Med J 2: 1257-1259

4. Vaughan NJA, Matthews JA, Kurtz AB, Nabarro JDN (1983) The bioavailability of circulating antibody-bound insulin following insulin withdrawal in Type 1 (insulin-dependent) diabetes. Diabetologia 24: $355-358$

5. Gray RS, Cowan P, Di Mario U, Clarke BF, Duncan LJP (1983) The influence of insulin binding antibodies on bovine and biosynthetic human insulin action in Type 1 diabetes. Diabetologia 25: 158 (Abstract)

6. Lloyd B, Burrin JM, Smyth P, Alberti KGMM (1978) Enzymatic fluorimetric continuous-flow assays for blood glucose, lactate, pyruvate, alanine, glycerol and 3-hydroxybutyrate. Clin Chem 24: 1724-1729

7. Nakagawa S, Nakayamah H, Sassaki T, Yoshino K, Yune YY, Shinozaki K, Aoki S, Mashimo K (1973) A simple method for the determination of free insulin levels in insulin treated patients. Diabetes $22: 590-600$

8. Soeldner J, Slone D (1965) Critical variables in the radioimmunoassay of serum insulin using the double antibody technique. Diabetes 14: 771-779
9. Reeves WG, Kelly U (1980) An immunochemical method for the quantitation of insulin antibodies. J Immunological Meth 34: 329-338

10. Home PD, Owens DR, Blain PG, Alberti KGMM (1982) A new look at the pharmacokinetics of subcutaneous injected human and porcine insulin. Diabetes 31:58A

11. Koivisto VA, Felig P (1980) Alterations in insulin absorption and in blood glucose associated with varying insulin injection sites in diabetic patients. Ann Internal Med 92: 59-61

12. Berger M, Cüppers HJ, Hegner H, Jörgens V, Berchtold P (1982) Absorption kinetics and biologic effects of subcutaneously injected insulin preparations. Diabetes Care 5: 77-91

13. Kinmouth AL, Baum JD (1980) Timing of pre-breakfast insulin injection and post-prandial metabolic control in diabetic children. Br Med J 280: 604-606

14. Francis AJ, Home PD, Hanning I, Alberti KGMM, Tunbridge WMG (1983) Intermediate acting insulin at bedtime: effect on blood glucose concentrations before and after breakfast. Br Med J 286: $1173-1176$

Received: 17 December 1984

and in revised form: 8 May 1985

Dr. A.J. Francis

Department of Medicine

The Medical School

Framlington Place

Newcastle upon Tyne NE2 4HH

UK 